\title{
Willingness to pay for rapid diagnostic tests for the diagnosis and treatment of malaria in southeast Nigeria: ex post and ex ante
}

\author{
Benjamin SC Uzochukwu ${ }^{1,3^{*}}$, Obinna E Onwujekwe ${ }^{2,3}$, Nkoli P Uguru $^{3}$, Maduka D Ughasoro ${ }^{4}$, \\ Ogochukwu P Ezeoke ${ }^{3}$
}

\begin{abstract}
Background: The introduction of rapid diagnostic tests (RDTs) has improved the diagnosis and treatment of malaria. However, any successful control of malaria will depend on socio-economic factors that influence its management in the community. Willingness to pay (WTP) is important because consumer responses to prices will influence utilization of services and revenues collected. Also the consumer's attitude can influence monetary valuation with respect to different conditions ex post and ex ante.

Methods: WTP for RDT for Malaria was assessed by the contingent valuation method using a bidding game approach in rural and urban communities in southeast Nigeria. The ex post WTP was assessed at the health centers on 618 patients immediately following diagnosis of malaria with RDT and the ex ante WTP was assessed by household interviews on 1020 householders with a prior history of malaria.

Results: For the ex ante WTP, 51\% of the respondents in urban and $24.7 \%$ in rural areas were willing to pay for RDT. The mean WTP (235.49 naira) in urban is higher than WTP (182.05 Naira) in rural areas. For the ex post WTP, 89 and $90.7 \%$ of the respondents in urban and rural areas respectively were WTP. The mean WTP (372.30 naira) in urban is also higher than (296.28 naira) in rural areas. For the ex post scenario, the lower two Social Economic Status (SES) quartiles were more willing to pay and the mean WTP is higher than the higher two SES while in the ex ante scenario, the higher two SES quartiles were more WTP and with a higher WTP than the lower two SES quartile. Ex ante and ex post WTP were directly dependent on costs.

Conclusion: The ex post WTP is higher than the ex ante WTP and both are greater than the current cost of RDTs. Urban dwellers were more willing to pay than the rural dwellers. The mean WTP should be considered when designing suitable financial strategies for making RDTs available to communities.
\end{abstract}

\section{Background}

Malaria is highly endemic in Nigeria and it remains one of the major public health problem in Nigeria and a leading cause of morbidity and mortality in the country [1]. With a prevalence rate of $919 / 100,000$, it accounts for $40 \%$ of disease burden reported at the public health facilities, $30 \%$ of all childhood deaths and $11 \%$ of maternal deaths. The loss to the economy as a direct result of malaria infections has been estimated as 132 billion Naira (US\$1.01 billion at an exchange rate of 130 Naira $=$ US\$1.00) [2].

\footnotetext{
* Correspondence: bscuzochukwu@yahoo.com
'Department of Community Medicine, College of Medicine, University of

* Correspondence: bscuzochukwu@yahoo.com
${ }^{1}$ Department of Community Medicine, College of Medicine, University of Nigeria, Enugu-campus, Nigeria
}

In most endemic countries, the diagnosis and treatment of malaria has traditionally relied on the clinical presentation of malaria symptoms due to lack of reliable microscopy in the majority of peripheral health units $[3,4]$ and microscopical examination of Giemsa-stained blood films. Syndromic approach is unreliable because the symptoms of malaria are non-specific, overlapping with other febrile diseases. Studies in Africa have shown that more than 50\% of patients clinically diagnosed with malaria have illnesses attributable to some other causes [5-7]. This results in over-diagnosis of malaria [8] over-prescription of antimalarial drugs, under-diagnosis and inappropriate treatment of non-malarial febrile illnesses (NMFI) [9-13]. 
On the other hand, even for the expert microscopist, microscopic diagnosis of malaria is time-consuming and labour-intensive. Although microscopy is considered to be the gold standard for malaria diagnosis $[14,15]$ in many malaria-endemic areas like Nigeria, there is lack of trained microscopists and reliable equipment.

Rapid diagnostic tests have considerable potential as tool to improve the diagnosis of malaria [16,17]. And its use in malaria diagnosis is increasing in many countries as the result of their ease of use with minimal training [18]. Using RDTs for diagnosis at the community level will shorten the time between onset of symptoms and initiation of appropriate treatment, leading to less suffering by the infected individual and less potential to spread the parasite to others when the infected individual is bitten by more anopheline mosquitoes. RDT use should also help slow development of resistance and reduce costs by avoiding unnecessary use of antimalarials. And with the introduction of the costly artemisininbased combination therapy (ACT) in sub-Saharan Africa, the use of RDTs has become more important in the control of malaria.

However any successful control of malaria will depend on socio-economic factors that influence its management in the community. There are multiple barriers to accessing formal healthcare among which is the cost of treatment $[19,20]$.

The availability of increased funding for malaria through the Global Fund for the AIDS, Tuberculosis and Malaria will increase the ability of health services in many endemic countries to purchase RDTs in large numbers. A challenge these countries will face is the building of a long term financial sustainable mechanism that can continue to support RDT use if the availability of funds is reduced in the future as access and affordability will be critical for the utilization of RDT. Thus an important issue is how much people are willing and able to pay for it. Several facts influence this decision;chance of utilizing such service, socio-economic status, availability of close alternative, prior exposure to product in question etc Furthermore, to make RDT easily accessible to all, government might need to take a decision on subsidy exemption and to do this, they require information on WTP.

In making pricing decisions, health program managers face an equity dilemma - the problem of balancing the need for programme sustainability with the social goal of making services available to low income clients [21] and hence increase coverage. Inferring from the law of demand it is generally difficult to achieve both coverage and sustainability especially in resource poor setting because as prices go up, demand will come down. Therefore willingness to pay (WTP) surveys allow programme managers to simulate price-related changes in demand without actually changing prices, giving them a way to make decisions based on empirical information. Thus, it also measures the potential demand for products or services by asking consumers, "Would you purchase this product if it were offered at this price?" They are frequently used in health, social and environmental programs for price setting and cost benefit analyses. WTP is important because consumer responses to prices will influence utilization of services and revenues collected. The consumer's attitude can also influence monetary valuation with respect to different conditions ex post and ex ante.

The correct population that has to provide their preferences in order to take resource allocation decisions in health care has been the subject of debate in the literatures [22]. There are theoretical arguments in favor of using members of the general population [23] as the relevant population and one reason is that when deciding whether a new health programme will be funded or not we should include the preferences of all subjects that can benefit from the program in the future. However, the main argument most frequently quoted in favor of using patients as subjects is that they are in a better position to value a medicine that improves their health. It has been argued that this framework provides a conservative estimate on WTP for health gains [24].

Individual preferences may not be independent of the consumer's vantage point. Allocations which appear desirable ex-ante may therefore not be so ex-post, since those who have used the product (ex-post) have a better understanding as there is no more health worker asymmetry of information. They are therefore more convinced in their decision be it price or making demand than those that have not be been exposed to the product (ex-ante). Thus differences observed between these groups represents to a greater extent the actual value of the product. In essence, the ex post WTP focuses on currently symptomatic persons who received the goods in question while the ex ante WTP focuses on currently non-symptomatic persons who are at future risk.

WTP has been used extensively in Nigeria for a variety of health care goods and services [25-28]. However, we are not aware of any WTP study in Nigeria with respect to RDTs. In this instance the WTP study sets out to identify the true demand for affordable and socially acceptable services, thus it is usually important to actively involve the consumers of these services in not only deciding if they want and can afford the test, but also if it satisfies their perceptions towards accurate diagnosis and cure of malaria [29].

The study therefore aims to determine WTP for RDTs across different socioeconomic groups in both urban and rural Nigeria where it has been newly introduced 
for the diagnosis of malaria in an era of change of first line antimalaria treatment to the expensive ACT. Since "WTP is inevitably associated with ability to pay" [30], the examination of WTP across socioeconomic and geographic groups could be used to ensure fairness in resource allocation. Furthermore to enact a policy, a reform has to be agreed, ex-ante preferred and ex-post desirable. Thus a reform which passes both tests is more likely to be enacted and has higher tendency to persist than one which does not. Since it is not possible to say anything about ex-post on the basis of ex-ante judgment, providing both ex-ante and ex-post information of willingness to pay for RDT to decision makers will be worthwhile.

\section{Methods}

The study was undertaken in Enugu East Local Government Area (LGA) in Enugu State, South-east Nigeria. It has six districts (Abakpa-Nike, Mbulujodo, Mbulu Oweghe, Mbulu Iyiukwu, Emene and Trans Ekulu) with a 2006 population of 279,089 [31]. While Abakpa-Nike, Trans-Ekulu and Emene are urban districts, the rest are rural. It has 12 Public Health centres and 30 Private clinics and hospitals. The number of health workers in these health centres range from 3 to 15 with the highly developed ones having more workers than the rest of the centres. All the centres have drug dispensing units but no laboratory facilities. Malaria is holoendemic in the rural areas and meso-endemic in the urban areas

\section{Study Design}

The study was part of a larger study that lasted for 30 months (to take care of the seasonal variations in malaria episodes) from 2005 to 2008 during which data was collected on all the different components of the study throughout the study period.

\section{Sample size calculation and sample selection}

For the ex ante, the software for population survey in EPI Info 6 as used for sample size calculation. The parameters that were used for sample size calculation were a power of $80 \%, 95 \%$ confidence level and considering $2 \%$ as the proportion of people with malaria that used services from the least commonly visited providers (community health workers) [32] for first treatment of malaria and an average of $6 \%$ monthly malaria incidence rate in the state. Hence, using the minimum projected population of each rural district at 30,000 people and each urban area at 60,000 people, it was estimated that a minimum of 1800 and 3600 people will have malaria monthly in each rural and urban area. The calculated minimum sample sizes for each urban site is 240 and for each rural site 221. However, allowing for a $10 \%$ refusal rate and ensuring an adequate sample size for data analysis for each district, the estimated sample sizes are 250 for rural, giving a total sample size in the two rural areas of 500 and 270 for urban giving a total sample size in the two urban areas of 540 . The overall sample size is 1020 .

The Primary Health Care (PHC) house numbering system was used as the sampling frame to select at least 1020 households from the study areas using simple random sampling technique. The primary woman household caregiver or in her absence, her spouse were interviewed using questionnaire administered by trained interviewers. The reliability of the observations was ensured by thoroughly training the field workers, strictly supervising the field-work and pre-testing the study tools to ensure that they are content valid. Eventually, information was collected from 1131 respondents.

A sample size of 136 was computed as the required number of blood smear positive patients for the health center survey, where RDT was administered. The calculation of the sample size was based on the following parameters: expected sensitivity of a test $=90 \%$, precision $=$ $5 \%$ and alpha error $=0.05$. This number $(n=136)$ was doubled taking into account a stratified analysis by age group category ( $0-4$ years and 5 years and above). Similar parameters (with expected specificity of 90\%) were used to calculate the required number of blood smear negative patients. The minimal final sample size was therefore fixed at 300 positive and 300 negative subjects, that is, 600 individuals for the RDT examination and therefore for the WTP ex post. All patients presenting at the centers with history of fever or non-specific symptoms or signs suggestive of malaria (e.g. headache only, chills, rigors) were consecutively recruited for the study.

\section{Data collection}

After informed consent has been signed, using pretested interviewer-administered questionnaire, the researchers collected information from the patients or the care takers regarding their socio-economic and demographic background, and their willingness to pay for RDT. WTP for RDT for Malaria was assessed by the Contingent valuation method (CVM), a survey-based method to determine individuals' monetary valuation of health care or health states [33-35] using a bidding game approach in rural and urban communities in southeast Nigeria. The ex post WTP was assessed at the health centers on 638 patients immediately following diagnosis of malaria with RDT and the ex ante WTP was assessed by household interviews on 1131 householders with a prior history of malaria. The scenario that described the RDT was presented to the respondents before WTP was elicited. RDT was described as $a$ new test kit which enables malaria to be diagnosed quickly even in remote areas, is easy to use by the health worker and the result is known within 15 minutes. In addition, for the ex post WTP, the respondents utilized the RDT. The starting amount used in the 
bidding game was derived from interviews conducted with Pharmacists to obtain the cost of RDTs in Enugu, Nigeria. Thus the market price was 200 Naira and we decided to mark up by 100 Naira for the starting bids and then increase or decrease by 100 Naira depending on the response to the starting bids. The respondents were allowed only three bids in order to decrease the complexity of the exercise to the respondents and the last bid represented their maximum WTP.

\section{Data analysis}

The data was entered, prepared and analyzed using the statistical computer programme SPSS 15 for Windows and STATA. The economic level of the households was used as a local relative indicator of wealth among the included households. The Principal components analysis (PCA) in STATA software package was used to generate continuous socio-economic status (SES) index using information of the households' asset holdings together with the average weekly cost of food. The assets were key ones that included ownership of motorcar, motorcycle, radio, refrigerator, television set, fan and bicycle. The SES index was decomposed into quartiles (4 groups) of SES groups. The 4 SES groups were: the highest SES group (Q4) or least poor; SES group (Q3) or poor; SES group $(\mathrm{Q} 2)$ or very poor and SES (Q1) or most poor. This was the used to measure the relationship between SES and WTP.

\section{Ethical considerations}

Approval of the study was granted by the ethics committee of the University of Nigeria Teaching Hospital Enugu. Informed written consent was sought from the patients or parents/caretakers of underage patients.

\section{Results}

\section{Socio-demographic characteristics of respondents}

As shown in table 1, of the 638 patients recruited for this study, 317 (49.7\%) and 321 (50.3\%) were from the urban and rural areas respectively. Majority of the respondents $423(66.3 \%)$ were above 30 years and more than a third of the ill persons 244 (38.2\%) were below 5 years of age. A majority of the ill persons 439 (68.8\%) are females, $538(84.3 \%)$. Most of them (81.7\%) had one form of formal education or the other. Their occupational status shows that petty traders are $139(21.8 \%)$, farmers 129(20.2), civil servants 97(15.2), self employed 101(15.8\%) and 91 (14.3\%) are unemployed.

In the household survey, the numbers of complete questionnaires that were available for data analysis were 576 and 555 in Urban and rural areas respectively (Table 2). The table shows that the respondents were mostly females in both areas. The respondents from the urban areas were expectedly more educated than those from the rural areas. The average years of formal schooling were 10.7 years in Urban and 7.1 years in rural area respectively. Most of the
Table 1 Respondents' socio-economic and demographic characteristics (Health center survey)

\begin{tabular}{|c|c|c|c|}
\hline & $\begin{array}{l}\text { Urban } \\
\mathrm{N}=317\end{array}$ & $\begin{array}{l}\text { Rural } \\
\mathrm{N}=321\end{array}$ & $\begin{array}{l}\text { Combined } \\
N=638\end{array}$ \\
\hline $\begin{array}{l}\text { Age of respondent (years): } \\
\text { Mean (SD) }\end{array}$ & $33.1(9.7)$ & $35.8(12.7)$ & $34.4(11.4)$ \\
\hline $\begin{array}{l}\text { Age of ill person: Mean } \\
\text { (SD) }\end{array}$ & $8.3(8.7)$ & $17.6(17.8)$ & $13.0(14.8)$ \\
\hline \multicolumn{4}{|l|}{ Sex of respondents } \\
\hline Females: $\mathrm{n} \%$ & $287(90.5)$ & $280(87.2)$ & $567(88.9)$ \\
\hline Males: n \% & $30(9.5)$ & $41(12.8)$ & $71(11.1)$ \\
\hline \multicolumn{4}{|l|}{ Sex of ill person } \\
\hline Females: $n \%$ & $215(67.8)$ & $224(69.8)$ & $439(68.8)$ \\
\hline Males: n \% & $102(32.2)$ & $97(30.2)$ & $199(31.2)$ \\
\hline $\begin{array}{l}\text { Years of education: Mean } \\
\text { (SD) }\end{array}$ & $9.2(4.5)$ & $6.7(5.0)$ & \\
\hline Whether married: $\mathrm{n} \%$ & $257(81.1)$ & $281(87.5)$ & $538(84.3)$ \\
\hline \multicolumn{4}{|l|}{ Occupation: n \% } \\
\hline Farmer & $19(6.0)$ & $110(34.3)$ & $129(20.2)$ \\
\hline Unemployed & $58(18.3)$ & $33(10.3)$ & $91(14.3)$ \\
\hline Civil servant & $99(31.2)$ & $40(12.5)$ & $97(15.2)$ \\
\hline Petty trading & $45(14.2)$ & $52(16.2)$ & $139(21.8)$ \\
\hline Self employed & $1(0.3)$ & $3(0.9)$ & $101(15.8)$ \\
\hline Big business man/woman & $17(5.4)$ & $2(0.6)$ & $19(3.0)$ \\
\hline Private employment & $28(8.8)$ & $13(22.7)$ & $4(0.6)$ \\
\hline Others & $27(8.5)$ & $3(0.9)$ & $30(4.7)$ \\
\hline Total & $317(100)$ & $321(100)$ & $638(100)$ \\
\hline \multicolumn{4}{|l|}{ SES quartiles } \\
\hline Q1 (most poor) & $61(19.2)$ & 99(30.8) & $160(25.1)$ \\
\hline Q2 (very poor) & $46(14.3)$ & $114(35.5)$ & $160(25.1)$ \\
\hline Q3 (poor) & 97 (30.6) & $62(19.3)$ & $159(24.9)$ \\
\hline Q4 (least poor) & 113 (35.6) & $46(14.3)$ & $159(24.9)$ \\
\hline Total & $317(100)$ & $321(10)$ & $638(100)$ \\
\hline
\end{tabular}

respondents in both areas were middle-aged, while the mean number of persons in a household is 5.5 and 4.7 in urban and rural areas respectively.

\section{Willingness to Pay}

As shown in table 3, for the ex post WTP, the willingness to pay for RDTs was positive for a majority of the respondents in both rural (90.7\%) and urban (89\%). The mean WTP in urban (372.30 naira) is higher than in rural areas (296.28 naira). In the combined data, the willingness to pay for RDTs was positive in $89.8 \%$ of the respondents and the mean WTP was 335.1 Naira. There was no statistical significant difference in WTP for RDT between the urban and rural dwellers $(p>0.05)$. For the ex ante WTP, the willingness to pay for RDTs was positive in $51 \%$ of the respondents in urban and $24.7 \%$ in rural areas. The mean WTP in urban (235.49 naira) is higher than mean WTP in rural areas (182.05 Naira). In the combined data, the willingness to pay for RDTs was positive in $38.1 \%$ of the respondents and the mean 
Table 2 Household Respondents' socio-economic and demographic characteristics

\begin{tabular}{|c|c|c|c|}
\hline & $\begin{array}{l}\text { Urban } \\
\mathrm{N}=576\end{array}$ & $\begin{array}{l}\text { Rural } \\
\mathrm{N}=555\end{array}$ & $\begin{array}{l}\text { Combined } \\
\mathrm{N}=1131\end{array}$ \\
\hline \multicolumn{4}{|l|}{ Respondent' status } \\
\hline Female head of household: $n \%$ & $22(3.8)$ & $119(21.4)$ & $141(12.5)$ \\
\hline Male head of household: $n \%$ & $16(2.8)$ & $48(8.6)$ & $64(5.7)$ \\
\hline Wife: n \% & $442(76.7)$ & $349(62.9)$ & 791 (69.9) \\
\hline Grandmother: n \% & $13(2.2)$ & $6(1.1)$ & $19(1.7)$ \\
\hline Representative of household: $n$ \% & $83(14.4)$ & $33(5.9)$ & $116(10.3)$ \\
\hline Whether married: n \% & $498(86.5)$ & $498(89.7)$ & $996(88.1)$ \\
\hline $\begin{array}{l}\text { People in the household: } \\
\text { Mean (SD): }\end{array}$ & $5.5(3.9)$ & $4.7(2.4)$ & $5.2(3.3)$ \\
\hline $\begin{array}{l}\text { Age of respondent (years): } \\
\text { Mean (SD) }\end{array}$ & $36.4(11.3)$ & $40.2(14.5)$ & $38.2(13.1)$ \\
\hline \multicolumn{4}{|l|}{ Sex of respondents } \\
\hline Females: $\mathrm{n} \%$ & $541(93.9)$ & $515(92.8)$ & $1056(93.4)$ \\
\hline Males: n \% & $35(6.1)$ & $40(7.2)$ & $75(6.6)$ \\
\hline Years of education: Mean (SD) & $10.7(3.7)$ & $7.1(5.7)$ & $8.9(5.1)$ \\
\hline \multicolumn{4}{|l|}{ Occupation: n \% } \\
\hline Farmer & $21(3.6)$ & $190(34.2)$ & $211(18.7)$ \\
\hline Unemployed & $86(14.9)$ & $66(11.9)$ & $152(13.4)$ \\
\hline Petty trading & $261(45.3)$ & $103(18.6)$ & $364(32.2)$ \\
\hline Civil servant & $96(16.7)$ & $68(12.3)$ & $164(14.5)$ \\
\hline Private employment & $20(3.5)$ & $19(3.4)$ & $39(3.4)$ \\
\hline Big business man/woman & $19(3.3)$ & $36(6.5)$ & $55(4.9)$ \\
\hline Self employed & $44(7.6)$ & $59(10.6)$ & $103(9.1)$ \\
\hline Others & $15(2.6)$ & $20(3.6)$ & $35(3.1)$ \\
\hline \multicolumn{4}{|l|}{ SES quartiles } \\
\hline Q1 (most poor): $\mathrm{n} \%$ & $222(38.5)$ & $61(11.0)$ & $283(25)$ \\
\hline Q2 (very poor): n \% & $78(13.5)$ & $204(36.8)$ & $282(24.9)$ \\
\hline Q3 (poor): n \% & $152(26.4)$ & $131(23.6)$ & $283(25.0)$ \\
\hline Q4 Least poor): n \% & $124(21.6)$ & 159 (28.6) & $283(25.0)$ \\
\hline
\end{tabular}

WTP was 209.27 Naira and there was a statistically significant difference in WTP for RDT between the urban and rural dwellers $(\mathrm{p}<0.05)$. In general, the ex post WTP was higher than the ex ante WTP.

Ex ante WTP was directly dependent on cost with $68.2 \%, 38.1 \%$ and $16.5 \%$ of respondents indicating willingness to pay 200 Naira, 300 Naira and 400 Naira respectively. Also, the ex post WTP was directly dependent on cost with $69.3 \%, 55.7 \%$ and $20.2 \%$ of respondents indicating willingness to pay 200 Naira, 300 Naira and 400 Naira respectively (table 4).

\section{Socioeconomic status (SES) differences in Willingness to Pay}

In the ex post WTP, the willingness to pay for RDTs was positive in 92.5 and $91.9 \%$ of the respondents in the lower SES quartiles (Q1 and Q2) respectively which was more than the 88.1 and $86.8 \%$ of the respondents in the higher SES (Q3 and Q4) respectively that recorded a willingness to pay. There was no statistically significant differences between them $(\mathrm{p}>0.05)$. The mean WTP (360.5 and 346.6 Naira) for Q1 and Q2 respectively are higher than in Q3 and Q4 which are 294.4 and 338.7 Naira respectively (Table 5 ).

For the ex ante WTP, the willingness to pay was positive for 47.0 and $47.2 \%$ of the respondents in the higher SES quartiles (Q3 and Q4) respectively which was more than the 27.9 and $30.5 \%$ of the respondents in the lower SES (Q1 and Q2) respectively that recorded willingness to pay. The difference was statistically significant ( $\mathrm{p}<$ 0.05). The mean WTP (158.9 and 194.79 Naira) for Q1 and Q2 respectively are lower than in Q3 and Q4 which are 232.54 and 251.67 Naira respectively (Table 5).

\section{Discussion}

In this study the currently symptomatic person (those who visited the health centers for RDT diagnosis) has more willingness to pay for the RDT. This is similar to what was obtained in Myanmar where those who were symptomatic had more willingness to pay for the diagnostic technology [36]. In microeconomic theory, demand-determining variables included tastes of the commodity consumed, among others[37]. In our study and in the Myanmar study [36], it was considered that the respondents provided the answer in accordance with their current taste of the RDT and thus better appreciates its benefits. Thus the decision to pay for RDT was propelled by need. It has also been noted that a recent

Table 3 Willingness to pay for RDT (130 Naira = 1 US Dollars)

\begin{tabular}{llll}
\hline Ex Post WTP & $\begin{array}{l}\text { Urban } \\
\mathbf{N}=\mathbf{3 1 7}\end{array}$ & $\begin{array}{l}\text { Rural } \\
\mathbf{N}=\mathbf{3 2 1}\end{array}$ & $\begin{array}{l}\text { Combined } \\
\mathbf{N}=\mathbf{6 3 8}\end{array}$ \\
\hline WTP: $\mathrm{n}(\%)$ & $282(89.0)$ & $291(90.7)$ & $573(89.8)$ \\
\hline Mean (SD) WTP (Naira) & $372.3(205.14)$ & $296.3(188.72)$ & $335.1(199.8)$ \\
& & & $0.5(0.479)$ \\
\hline Ex ante WTP & Urban & Rural & Combined \\
\hline WTP: $n$ (\%) & $\mathrm{N}=576$ & $\mathrm{~N}=555$ & 1131 \\
Mean (SD) WTP (Naira) & $294(51.0)$ & $137(24.7)$ & $431(38.1)$ \\
\hline
\end{tabular}

NA = Not applicable

*Statistically significant 
Table 4 Respondents' willingness to pay amount

\begin{tabular}{lll}
\hline WTP amount (naira) & $\begin{array}{l}\text { Ex post WTP } \\
\mathbf{N}=\mathbf{5 7 3} \\
\mathbf{N}(\%)\end{array}$ & $\begin{array}{l}\text { Ex ante WTP } \\
\mathbf{N}=\mathbf{4 3 1} \\
\mathbf{N}(\%)\end{array}$ \\
\hline 200.00 and less & $397(69.3)$ & $294(68.2)$ \\
300.00 & $319(55.7)$ & $164(38.1)$ \\
400.00 and more & $116(20.2)$ & $71(16.5)$ \\
\hline
\end{tabular}

Table 5 Socioeconomic status (SES) differences in WTP for RDT. (130 Naira = 1 US Dollars)

\begin{tabular}{|c|c|c|c|c|}
\hline \multirow[b]{2}{*}{$\begin{array}{l}\text { SES } \\
\text { quartiles }\end{array}$} & \multicolumn{2}{|c|}{$\begin{array}{c}\text { Ex post WTP } \\
\mathrm{N}=573\end{array}$} & \multicolumn{2}{|c|}{$\begin{array}{c}\text { Ex ante WTP } \\
\mathrm{N}=431\end{array}$} \\
\hline & $\begin{array}{l}\text { WTP } \\
\text { No (\%) }\end{array}$ & $\begin{array}{l}\text { Mean (SD) } \\
\text { WTP } \\
\text { (Naira) }\end{array}$ & $\begin{array}{l}\text { WTP } \\
\text { No (\%) }\end{array}$ & $\begin{array}{l}\text { Mean (SD) } \\
\text { WTP } \\
\text { (Naira) }\end{array}$ \\
\hline $\begin{array}{l}\text { Q1 (most } \\
\text { poor): }\end{array}$ & $148(92.5)$ & $360.5(240.3)$ & 79 (27.9) & $158.90(146.2)$ \\
\hline $\begin{array}{l}\text { Q2 (very } \\
\text { poor) }\end{array}$ & 147 (91.9) & $346.6(215.3)$ & $86(30.5)$ & 194.79 (175.9) \\
\hline $\begin{array}{l}\text { Q3 (very } \\
\text { poor): }\end{array}$ & $140(88.1)$ & $294.4(136.5)$ & $133(47.0)$ & $232.54(162.2)$ \\
\hline $\begin{array}{l}\text { Q4 (Least } \\
\text { poor): }\end{array}$ & $138(86.8)$ & $338.7(201.2)$ & $133(47.2)$ & $251.67(210.4)$ \\
\hline Total: & $573(89.8)$ & $335.1(199.8)$ & $431(38.1)$ & $209.27(178.6)$ \\
\hline $\begin{array}{l}\text { Chi square } \\
\text { for trend }\end{array}$ & 4.13 & NA & 38.7 & NA \\
\hline$P$ value & 0.248 & NA & $0.000^{*}$ & NA \\
\hline
\end{tabular}

$\mathrm{NA}=$ Not applicable

*Statistically significant

episode in a household was associated with increased WTP [38].

In the ex ante scenario, the urban dwellers were more willing to pay for RDT. This might be due to the fact that they are more educated and therefore appreciate the usefulness of RDT. The mean years of education in urban is 10.7 years as against 7.1 years for the rural dwellers. The level of education has been significantly linked to WTP $[25,27]$ because with increasing education level, there is assumed higher awareness about health care needs, resulting in the will to pay for personal and household protection [25].

The mean WTP of the poorest quartiles for the ex ante scenario was less than those from the least poor quartiles. It has been noted that the more income an individual has, the greater the WTP, which is consistent with welfare economic theory [36]. However, the response is different with those who utilized RDT. Here the poorest were more willing to pay and to even pay a higher amount. And this is contrary to the findings of Donaldson et al. [30] that showed that those with a lower ability to pay were less likely to be willing to pay for healthcare. The reason for the poorest being more willing to pay might be because they are poor and therefore suffer more from malaria and their experience with the use of RDT might be seen by them as a way of treating the malaria faster and thus saving them some cost. It has been noted that socioeconomic differentials exists in access to malaria interventions increasing the vulnerability of the poorest [39]. Despite the fact that the poor are willing to pay for RDTs, it is important to ensure that strategies put in place to improve the management of malaria such as RDTs are equitable and available and accessible to the poorest SES groups because they bear a disproportionate burden of the disease and have poor health-seeking behavior [40].

The fact that the elicited WTP ex post and ex ante are greater than the current market price of RDT is quite encouraging and is a reflection of the fact that the community value RDTs highly and are willing to utilize it if available. In some contexts charging for malaria prevention strategies like mosquito nets was associated with high levels of uptake among the poorest quintiles [38]. Thus the government and healthcare providers can be assured of sustained financial mechanisms to ensure constant availability and increased coverage.

It should be noted that on the whole, the use of RDTs lowers the cost of malaria because they produce quick and accurate diagnosis of malaria, thereby decreasing the length of morbidity, while also increasing productivity. It is therefore worthwhile encouraging the communities to utilize it. Within the context of increasing antimalarial costs and or decreasing malaria transmission, the importance of limiting antimalarial treatment to only those confirmed as having malaria parasites is very important [41]. Therefore the use of RDTs would considerably reduce over-treatment and wrong diagnosis which is seen in cases where presumptive diagnosis is used [42] thereby reducing the cost of treating malaria to the individual.

Although the respondents were asked how much they were willing to pay for RDTs after narrating the scenario to them and after diagnosis with RDTs as the case may be, we did not ask the respondents to state why they would like to pay more or less than the market price of RDT. It is our believe that their responses is a reflection of their valuation of the RDTs. However, we note this as a limitation of the study and a gap that needs to be filled in future studies with more appropriate qualitative methods.

\section{Conclusions}

Respondents are willing to pay for RDTs and ex post WTP is higher than the ex ante WTP. For a wider distribution of RDTs in Nigeria to enable fast diagnosis and correct treatment of malaria cases with ACT, the government should consider providing the RDTs free of charge or subsidize them for the poorest socio-economic status consumers (despite their willingness to pay) and other vulnerable groups, like pregnant women. This is important 
because setting the user fees at mean WTP for instance does not necessarily ensure universal access as all those with below mean WTP will be denied access while those with above mean WTP will earn consumer surplus. Therefore, government and donor agencies should consider the possibility for subsidization - public or private - and/or the possibility of price discrimination. The National Insurance Scheme (NHIS) could provide this cross subsidization if the NHIS is scaled up in Nigeria.

Furthermore, government and donors should appreciate the benefits of decreasing overall societal costs of malaria and increasing societal productivity if RDTs are appropriately deployed for diagnosis and subsequent treatment of malaria, and this calls for public financing of the intervention. However, social marketing and health education campaigns can be used to convince householders on how to convert some of their current expenditures on some inappropriate treatment to purchase of RDTs for diagnosing malaria. Governments and donors should be willing to commit funds to make RDTs affordable especially to the poorest consumers and other vulnerable members of the society if the intervention is to be used to significantly reduce the burden of malaria. We are aware that this single study may not be a guarantee for generalization in Nigeria, but it provides some evidence to guide policy makers.

\section{Acknowledgements}

We would like to thank all patients and respondents who consented to participate in this study, and staff of Health Policy Research Group, College of Medicine, University of Nigeria, Enugu-campus. The study was funded by the UNICEF/UNDP/World Bank/WHO Special Programme for Research and Training in Tropical Diseases (TDR).

\section{Author details}

'Department of Community Medicine, College of Medicine, University of Nigeria, Enugu-campus, Nigeria. ${ }^{2}$ Department of Health Administration and Management, College of Medicine, University of Nigeria, Enugu-campus, Nigeria. ${ }^{3}$ Health Policy Research Group, College of Medicine, University of Nigeria, Enugu-campus, Nigeria. ${ }^{4}$ Department of Paediatrics, University of Nigeria, Teaching Hospital Enugu, Nigeria.

\section{Authors' contributions}

BSCU conceived and designed the study, BSCU, MDU collected the data, BSCU and OEOanalysed the data. BSCU wrote up the manuscript with input from all the authors. All authors read and approved the final manuscript.

\section{Competing interests}

The authors declare that they have no competing interests.

Received: 2 June 2009

Accepted: 15 January 2010 Published: 15 January 2010

\section{References}

1. Federal Ministry of Health [FMOH]: National Antimalaria Treatment Policy. Federal Ministry of Health, Abuja, Nigeria 2007.

2. Malaria Consortium: Support to the National Malaria Programme, Nigeria. A DFID-Funded Project (2008-2012) 2008.

3. Chandler $C I R$, Jones $C$, Boniface $G$, et al: Guidelines and mindlines: why do clinical staff over-diagnose malaria in Tanzania? A qualitative study. Malaria Journal 2008, 7:53.
4. Makani J, Matuja W, Liyombo E, Snow RW, March K, Warrell DA, et al: Admission diagnosis of cerebral malaria in adults in an endemic area of Tanzania: implications and clinical description. Q J Med 2003, 96:355-362. 5. Bandon D, et al: A study of malaria morbidity in a rural area of Burkina Faso. Transaction of the Royal Society of Tropical Medicine and Hygiene 1985, 79:283-284.

6. Genton B, et al: Malaria: how useful are clinical criteria for improving the diagnosis in a highly endemic area?. Transactions of the Royal Society of Tropical Medicine and Hygiene 1994, 88:537-541.

7. Amexo M, Tolhurst R, Barnish G, Bates I: Malaria misdiagnosis: effects on the poor and vulnerable. Lancet 2004, 364:1896-8.

8. Reyburn H, Mbakilwa H, Mwangi R, Mwerinde O, Olomi R, Drakeley C, Whitty CJ: Rapid diagnostic tests compared with malaria microscopy for guiding outpatient treatment of febrile illness in Tanzania: randomised trial. BMJ 2007, 334:403.

9. Bloland PB, Kachur SP, Williams HA: Trends in antimalarial drug deployment in sub-Saharan Africa. J Exp Biol 2003, 206(21):3761-3769.

10. Barnish G, Bates I, Iboro J: Newer drug combinations for malaria. Br Med J 2004, 328:1511-2.

11. Nosten F, Ashley E: The detection and treatment of Plasmodium falciparum malaria: Time for change. J Postgrad Med 2004, , 1: 35-39.

12. Lubell $Y$, Hopkins H, Whitty CJM, Staedke SG, Mills A: An interactive model for the assessment of the economic costs and benefits of different rapid diagnostic tests for malaria. Malaria Journal 2008, 7:21, doi:10.1186/14752875-7-21.

13. Zurovac D, Midia B, Ochola SA, English M, Snow RW: Microscopy and outpatient malaria case management among older children and adults in Kenya. Trop Med Int Health 2006, 11:432-40.

14. Bell D, Peeling RW: Evaluation of rapid diagnostic tests: malaria. Nature Rev Microbiol 2006, 4(suppl):S7-S20.

15. Hamer DH, Ndhlovu M, Zurovac D, Fox M, Yeboah-Antwi K, Chanda P, Sipilinyambe N, Simon JL, Snow RW: Improved diagnostic testing and malaria treatment practices in Zambia. JAMA 2007, 297:2227-31.

16. World Health Organization: The role of laboratory diagnosis to support malaria disease management: Focus on the use of rapid diagnostic tests in areas of high transmission. Report of a WHO Technical Consultation, 2526 October 2004 World Health Organization; Geneva 2006.

17. Bell D, Wongsrichanalai C, Barnwell JW: Ensuring quality and access for malaria diagnosis: how can it be achieved?. Nat Rev Microbiol 2006, 4:68295.

18. Mayxay M, Newton PN, Yeung S, Pongvongsa T, Phompida S, Phetsouvanh $\mathrm{R}$, White NJ: Short communication: An assessment of the use of malaria rapid tests by village health volunteers in rural Laos. Trop Med Int Health 2004, 9:325-329.

19. Nyamongo IK: Health care switching behaviour of malaria patients in a Kenyan rural community. Soc Sci Med 2002, 54:377-386.

20. Onwujekwe O, Uzochukwu B, Eze S, Obikeze E, Okoli C, Ochonma O: Improving equity in malaria treatment: relationship of socio-economic status with health seeking as well as with perceptions of ease of using the services of different providers for the treatment of malaria in Nigeria. Malar J 2008, 7:5.

21. Foreit KF, Foreit JR: Willingness to Pay surveys for setting prices for reproductive health products and services. A User's manual. 2004.

22. Ubel PA, Richardson J, Menzel P: Societal value, the person trade-off, and the dilemma of whose values to measure for cost-effectiveness analysis. Health Econ 2000, 9(2):127-36.

23. O'Brien B, Gafni A: When do the "dollars" make sense? Toward a conceptual framework for contingent valuation studies in health care. Med Decis Making 1996, 16(3):288-99.

24. Johannesson M: A note on the relationship between ex ante and expected willingness to pay for health. Soc Sci Med 1996, 42(3):305-11.

25. Onwujekwe OE, Shu EN, Nwagbo D, Akpala CO, Okonkwo PO: Willingness to pay for community-based ivermectin distribution: A study of three onchocerciasis-endemic communities in Nigeria. Tropical Medicine and International Health 1998, 3(10):802-808.

26. Onwujekwe O, Shu E, Chima R, Onyido A, Okonkwo P: Willingness to pay for the retreatment of mosquito nets with insecticide in four communities of south-eastern Nigeria. Tropical Medicine and International Health 2000, 5(5):370-376.

27. Onwujekwe O, Uzochukwu B, Shu E, Ibeh C, Okonwo P: Is combination therapy for malaria based on user-fees worthwhile and equitable to 
consumers?. Assessment of costs and willingness to pay in southeast Nigeria. Acta Tropica 2004, 91(2):101-115.

28. Uzochukwu BSC, Onwujekwe OE: Altruistic willingness to pay for family planning services: a study in Southeast Nigeria. Nigerian Journal of Community Medicine and Primary Health Care 2003, 15(2):47-56.

29. Willingness to pay studies. http://www.stoveco.com/wtp.html, (assessed 18 October, 2009).

30. Donaldson C, Farrar S, Mapp T, Walker A, McPhee S: Assessing community values in health care: is the 'willingness to pay' method feasible?. Health Care Analysis 1997, 5:7-29.

31. Federal Government of Nigeria (FGN): Legal Notices on publication of the details of the breakdown of the National and State Provisional population census totals. Official Gazette, Lagos 2007, 94(24).

32. Uzochukwu BSC, Onwujekwe OE: Socio-economic differences and health seeking behaviour for the diagnosis and treatment of malaria: a case study of four local government areas operating the Bamako Initiative programme in south-east Nigeria. Int J Equity Health 2004, 3:6-16.

33. Diener A, O'Brien B, Gafni A: Health care contingent valuation studies: a review and classification of the literature. Health Econ 1998, 7:313-326.

34. Klose T: Review: The contingent valuation method in health care. Health Policy 1999, 47:97-123.

35. Bhatia MR, Fox-Rushby JA: Willingness to pay for treated mosquito nets in Surat, India: the design and descriptive analysis of a household survey. Health Policy Plan 2002, 17:402-411.

36. Cho-Min-Naing, Lertmaharit S, Kamol-Ratanakul P, Saul JA: Ex post and ex ante willingness to pay (wtp) for the ICT malaria $p f / p v$ test kit in Myanmar. Southeast Asian J Trop Med Public Health. 2000, 31(1):104-111.

37. Pindyck RS, Rubinfeld DL: Shifts in supply and demand. Microeconomics New Jersey: Prentice-Hall international, 4 1998, 22.

38. Onwujekwe O, Hanson K, Fox-Rusbby J: Inequities in acquisition of mosquito nets and willingness to pay for insecticide-treated nets in Nigeria: Challenges to successes of malaria control interventions. Malaria Journal 2004, 3:6.

39. Worral E, Basu S, Hanson K: Is malaria a disease of poverty? A review of literature. Trop Med Int Health 10:1047-1059.

40. Onwujekwe O, Ojukwu J, Uzochukwu B, Dike N, Shu E: Where do people from different socioeconomic groups receive diagnosis and treatment of malaria in southeast Nigeria. Ann Trop Med Parasitol 2005, 99:177-182.

41. Zikusooka CM, Mclntyre D, Barnes Kl: Should countries implementing an Artemisinin based combination treatment policy also introduce rapid diagnostic tests?. Malar J 2008, 7:176.

42. Rolland $E$, Checchi $F$, et al: Operational response to malaria epidemics: are rapid diagnostic tests cost-effective?. Trop Med Int Health 2006, 11(4):398-408.

\section{doi:10.1186/1475-9276-9-1}

Cite this article as: Uzochukwu et al: Willingness to pay for rapid diagnostic tests for the diagnosis and treatment of malaria in southeast Nigeria: ex post and ex ante. International Journal for Equity in Health 2010 9:1

\section{Publish with Bio Med Central and every scientist can read your work free of charge}

"BioMed Central will be the most significant development for disseminating the results of biomedical research in our lifetime. "

Sir Paul Nurse, Cancer Research UK

Your research papers will be:

- available free of charge to the entire biomedical community

- peer reviewed and published immediately upon acceptance

- cited in PubMed and archived on PubMed Central

- yours - you keep the copyright
BioMedcentral 